\title{
Downscaling future wind hazard for SE London using the UKCP09 regional climate model ensemble
}

\author{
S. Blenkinsop ${ }^{1, *}$, Y. Zhao ${ }^{2}$, J. Quinn ${ }^{4}$, F. Berryman ${ }^{3}$, J. Thornes ${ }^{5}$, C. Baker ${ }^{4}$, \\ H. J. Fowler ${ }^{1}$ \\ ${ }^{1}$ School of Civil Engineering and Geosciences, Newcastle University, Newcastle upon Tyne NE1 7RU, UK \\ ${ }^{2}$ Manufacturing Department, School of Applied Sciences, Cranfield University, Cranfield, Bedfordshire MK43 0AL, UK \\ ${ }^{3}$ School of Engineering and the Built Environment, University of Wolverhampton, Telford Campus, Telford TF2 9NT, UK \\ ${ }^{4}$ School of Civil Engineering and ${ }^{5}$ School of Geography, Earth and Environmental Sciences, University of Birmingham, \\ Birmingham B15 2TT, UK
}

\begin{abstract}
Extreme weather events present a risk to urban communities, which under future climate change may require greater resilience to reduce susceptibility to potential damage and loss of life. Improved resilience requires detailed information on both current and future levels of weather-related hazards; however, climate models do not provide output at a sufficiently high resolution to provide usable information at the city scale. Furthermore, uncertainties in future climate projections need to be communicated in an appropriate manner to facilitate better local decisionmaking and adaptation. This paper addresses the problem of providing local-scale projections of hazards associated with high wind speeds over south-east London, along with quantified estimates of uncertainty. It describes a 2-step method for downscaling daily mean wind speed from a $25 \mathrm{~km}$ regional climate model (RCM) perturbed physics ensemble. This links climatological bias correction and engineering downscaling approaches to derive projections of maximum hourly mean wind speed and maximum 3 second gust speed at a resolution of $1 \mathrm{~km}$. This employs temporal downscaling factors that have previously been used to estimate structural loading on new buildings but are here implemented at the city scale. The ensemble indicates that future changes in mean daily wind speed for the 2050s are not significantly different to those for a baseline period (1961-1990). Further, whilst the area is projected to experience an increase in exposure to events with the potential to cause damage to buildings, changes are small and considerable uncertainties remain in modelling such extremes.
\end{abstract}

KEY WORDS: Wind · Downscaling $\cdot$ Regional climate models $\cdot$ UKCP09 $\cdot$ Ensemble $\cdot$ Extreme weather · Hazard

Resale or republication not permitted without written consent of the publisher

\section{INTRODUCTION}

Extreme weather events (EWEs) pose a significant risk to society, and so many studies have examined the changes in precipitation and temperature EWEs projected by climate models as a consequence of anthropogenic climate change (e.g. Karl et al. 1999, Kjellström et al. 2007, Fowler \& Ekström 2009, Fowler et al. 2010). However, high wind speeds may be inju- rious to human health, cause damage to crops and trees and damage ecosystems (Beniston et al. 2007). They may also adversely affect urban environments, reducing the safety of transport systems (Alcamo et al. 2007). Model projections suggest that climate change may lead to an increase in financial losses related to windstorms across many parts of Europe (Schwierz et al. 2010), although the relationship between climate change and financial losses cannot 
be easily quantified in the context of complex societal and economic change. Windstorms have been identified as 1 of 5 key risks that may impact on human health in London as a consequence of climate change (Mayor of London 2007) and as a potential risk to infrastructure (City of London 2010).

The ability of local communities to increase their resilience to, and cope with, the impact of EWEs is dependent on their access to information on both the current and future occurrence and magnitude of these events, their likely impacts on the community and the inclusion of EWE risks in planning decisions. Challenges which must be addressed to improve the ability of local communities to increase resilience and to make robust decisions include the use of models that capture spatial variability, the provision of information that is useful to a wide range of users and also the communication of uncertainties inherent in projections of future climate.

General circulation models (GCMs) are the main tool by which future projections of global climate may be simulated, but these have too coarse a resolution for assessing local scale impacts and vulnerabilities to climate change. This issue may be addressed through downscaling climate model output using either dynamical or statistical methods. Reviews of downscaling are provided by Wilby \& Wigley (1997) and Fowler et al. (2007).

The process of dynamical downscaling uses regional climate models (RCMs) that derive boundary conditions from GCMs and provide output at a higher resolution (typically 25 to $50 \mathrm{~km}$ ). These have demonstrated mixed skill in the simulation of wind extremes (Christensen et al. 2007); for example, an ensemble experiment covering Europe performed by the EU PRUDENCE project provided realistic simulations over sea but underestimated high wind speeds over land and coastal areas (Rockel \& Woth 2007). Systematic biases in the simulation of extreme wind speeds over Europe by RCMs have also been detected over areas of complex orography (Donat et al. 2010). Over the UK, an experiment using an RCM version of HadCM3 underestimated extreme wind speeds over Scottish and west coast stations and overestimated them over southern inland stations (Brown et al. 2008). Confidence in future projections of regional wind climatology is therefore relatively low, especially as Schwierz et al. (2010) suggest that the largest uncertainties may be associated with the most extreme events. Nonetheless, RCM experiments project a likely increase in average and extreme wind speeds in northern Europe in the future (e.g. Räisänen et al. 2004, Beniston et al. 2007, Christensen et al. 2007), although this pattern may be highly spatially variable (Nikulin et al. 2011) and sensitive to model selection (Kjellström et al. 2011).

The higher resolution output provided by RCMs, however, remains insufficient to use as a basis for robust decision making in response to many climate change impacts. Statistical methods have been widely employed to downscale temperature and precipitation to a finer resolution, but have been applied less frequently to wind. For example, Pryor et al. (2005) downscaled the Weibull parameters of wind speed probability distributions for an ensemble of GCMs using a multiple linear regression approach, whilst Najac et al. (2009) also downscaled a GCM ensemble but used a weather typing approach. Other methods have also been applied to reanalysis data (e.g. empirical orthogonal functions, Davy et al. 2010; generalized additive models, Salameh et al. 2009) and to numerical weather prediction models (stochastic differential equations; Bernardin et al. 2009). In urban environments, RCM wind data have been downscaled using models of urban canyons and open spaces at individual locations to identify areas at risk from high winds (Cui et al. 2004).

To date there has been relatively little work examining the projected impacts of high wind speeds at the city or borough scale. Although Smith \& Lawson (2012) provide a comprehensive assessment of current EWEs for Manchester, other city-scale analyses of climate change impacts have tended to focus on flooding, heat extremes and water resource availability (Hunt \& Watkiss 2011) and are not focused on specific community hazards. The research described here is part of the Severe Weather Events Risk and Vulnerability Estimator (SWERVE) project that seeks to use state-of-the-art simulations from the UK Climate Projections (UKCP09; Murphy et al. 2010) to further our understanding of the current and future risk of a range of extreme weather related hazards for a study area in south-east London. The SWERVE project forms part of a larger multi-disciplinary research project: Community Resilience to Extreme Weather (CREW; Blenkinsop et al. 2010a), which seeks an improved understanding of the risks, vulnerabilities, barriers and drivers that affect the resilience of a local community to EWEs and climate change.

In this paper therefore, we consider the current and future hazards posed by wind, linking a perturbed physics RCM ensemble provided by UKCP09 with a downscaling method traditionally used for the estimation of site-specific structural loadings on new urban construction. This seeks to demonstrate how established engineering approaches may be linked 
with climate downscaling methodologies to provide stakeholders with projections of current and future city-scale hazards.

\section{STUDY AREA AND DATA}

The South East London Resilience Zone (SELRZ; Fig. 1) covers an area $\sim 380 \mathrm{~km}^{2}$, comprising the 5 London boroughs of Lewisham, Greenwich, Bexley, Croydon and Bromley $\left(51.3-51.5^{\circ} \mathrm{N}, 0.15^{\circ} \mathrm{W}-0.2^{\circ} \mathrm{E}\right)$ with a total population of $\sim 1.3$ million people at the 2001 census. South-east London contains over 15\% of London's industrial land area and provides over 500000 jobs. The London Plan (Mayor of London 2008) has designated this area important for London's future strategic objectives and among its priorities is ensuring that the effects of climate change are authoritatively assessed and that effective measures to address it are incorporated in new developments. The SELRZ is therefore ideally suited to investigation within the CREW project.

\subsection{Climate model ensemble and data}

\subsubsection{Observed data}

RCM simulations of daily mean wind speed $\left(V_{\mathrm{D}}\right)$ were assessed using 2 observed datasets. Firstly, observed daily wind speed data were obtained from the MIDAS dataset $\underline{1}$. Daily mean $10 \mathrm{~m}$ wind speed

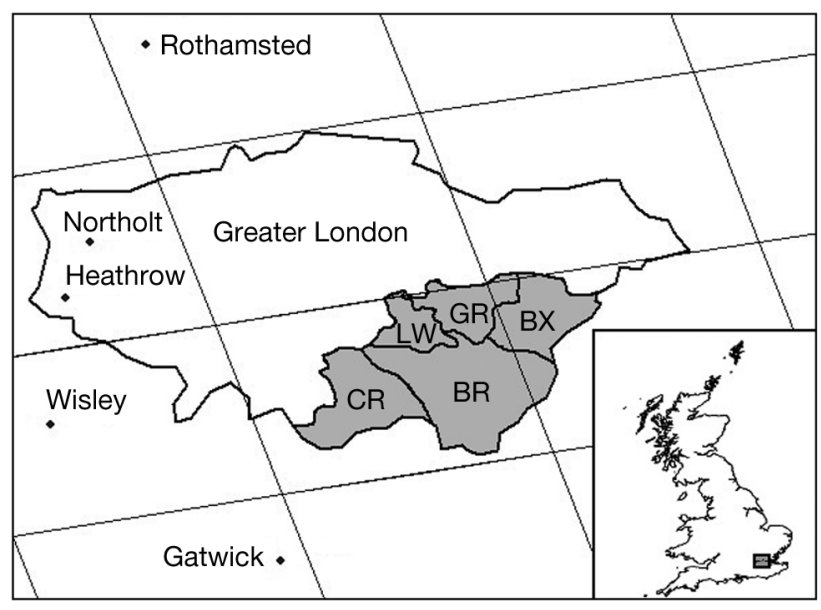

Fig. 1. South East London Resilience Zone (SELRZ) (shaded area) comprising the London boroughs of Lewisham (LW), Greenwich (GR), Bexley (BX), Croydon (CR) and Bromley $(B R) .(\diamond)$ : Locations for which complete observed daily mean wind speed records exist for the 1961-1990 baseline period. RCM $25 \mathrm{~km}$ grid cells shown data were extracted for the 1961-1990 baseline period for all weather stations within one RCM grid cell of the Greater London area (see Fig. 1). Secondly, a $5 \mathrm{~km}$ resolution gridded monthly $10 \mathrm{~m}$ mean wind speed dataset for the period 1969-2006 has been made available by UKCP09². Data was extracted for the period 1969-1990 to provide a reliable estimation of the mean wind climatology over the baseline. Details of the gridding procedure for this dataset are provided by Jenkins et al. (2008), and a description of the dataset construction using records from 70 stations ( 1 station per $59 \times 59 \mathrm{~km}^{2}$ ) is given by Perry \& Hollis (2005). A comparison of mean monthly wind speed for the station data and corresponding grid cells in the $5 \mathrm{~km}$ dataset demonstrated a good agreement (not shown) between the 2 datasets.

\subsubsection{UKCP09 RCM ensemble}

The UK Climate Projections (UKCP09; Murphy et al. 2010) provide an 11-member transient perturbed physics ensemble (PPE) ${ }^{3}$ comprising 11 variants of the Hadley Centre's RCM HadRM3 by varying uncertain parameters within plausible ranges. The ensemble dynamically downscales simulations of the fully coupled atmosphere-ocean GCM HadCM3 with each RCM variant using parameter settings selected to be consistent with those used in the relevant driving GCM variant. The ensemble provides daily climate data at a resolution of $25 \mathrm{~km}$ for the transient period from 1950 to 2100 under the SRES A1B (medium) emissions scenario for the future period. The ensemble does not incorporate the full range of uncertainty provided by the UKCP09 probabilistic projections, as the latter samples the full parameter space of the HadCM3 atmosphere model and also accounts for the contribution of uncertainty from other climate models, as well as those arising from biogeochemical cycles (Murphy et al. 2010). Probabilistic projections of changes in wind speed have recently been added to the UKCP09 database (Sex-

\footnotetext{
1 The MIDAS dataset provides daily and hourly land surface data and may be downloaded from the British Atmospheric Data Centre (BADC) at http://badc.nerc.ac.uk/view/badc. nerc.ac.uk_ATOM_dataent_ukmo-midas

${ }^{2}$ This data is available to download from the UK Meteorological Office subject to approval at www.metoffice.gov.uk/ climatechange/science/monitoring/ukcp09/index.html ${ }^{3}$ This data has been made available by the Climate Impacts Link project and may be downloaded from the BADC at http://badc.nerc.ac.uk/view/badc.nerc.ac.uk_ATOM_da taent_12178667495226008
} 
ton \& Murphy 2010) but simulations of future daily wind speed needed for impact studies may only be obtained from the 11-member PPE.

In the CREW project, the 2020s (SCN20) and 2050s (SCN50) were identified as near- to medium-term future periods of greatest interest to stakeholders. The analysis of future RCM projections and downscaled hazard information was therefore limited to two 30-yr periods centred on each of these decades. In addition, to provide information on current hazards and to serve as a baseline (BSL) against which to assess future projections, daily mean wind speeds were also extracted from the RCMs for the period 1961-1990. Providing downscaled estimates of extreme wind events will provide additional information to that available at a coarse resolution elsewhere (e.g. Brown et al. 2008).

\section{DOWNSCALING ENSEMBLE WIND PROJECTIONS FOR IMPACT STUDIES}

In this section we describe a 2-step process that first performs a bias correction of the RCM ensemble daily mean wind speed data and then downscales the corrected daily means to provide gust data at a spatial resolution of $1 \mathrm{~km}$. compared with daily mean wind speeds from the MIDAS dataset for nearby observed weather station time series (Fig. 1) at Heathrow, Gatwick, Wisley, Rothamsted and Northolt. Fig. 2 shows that, with respect to both station and gridded series, the ensemble is reasonably skilful in capturing the annual variability in mean wind speed, simulating higher speeds in winter (DJF) and early spring than summer (JJA). However, across the SELRZ there is a positive bias of $22 \%$ annually with respect to the UKCP09 gridded dataset (31\% in DJF and 19\% in JJA). This confirms a systematic overestimation of mean daily wind speed across the ensemble consistent with that provided by Brown et al. (2009) and their identified need for a bias correction strategy for the RCM data.

To determine an appropriate bias correction method the observed distribution of mean daily wind speed was compared with those for each RCM ensemble member. The nearest appropriate observed daily dataset was identified as Heathrow, which offers a complete record over the 1961-1990 period and closely reflects the monthly mean distribution of wind speed derived from the UKCP09 gridded dataset (shown in Fig. 2). An examination of monthly mean wind speeds for the gridded UKCP09 observed data also indicated relatively little spatial variability, with means for the

\subsection{Quantile correction of RCM mean daily wind speed}

Evidence of bias in the daily RCM data obtained from the 11-member PPE was identified by Brown et al. (2009) who indicated positive biases compared with an interpolated observed dataset in the range of 10 to $30 \%$ across much of the Midlands and the south east of England. A major difficulty for validating the RCM at specific locations across the SELRZ is the scarcity of observed wind speed data, so this was achieved by comparing the RCM data for the BSL period with the $5 \mathrm{~km}$ UKCP09 monthly mean wind speed dataset. Mean monthly wind speeds for the twentythree $5 \mathrm{~km}$ grid cells corresponding to the SELRZ were compared with those for the RCM ensemble (using the RCM grid cell containing most of the SELRZ) to provide a first-order comparison (Fig. 2). The RCM ensemble was also

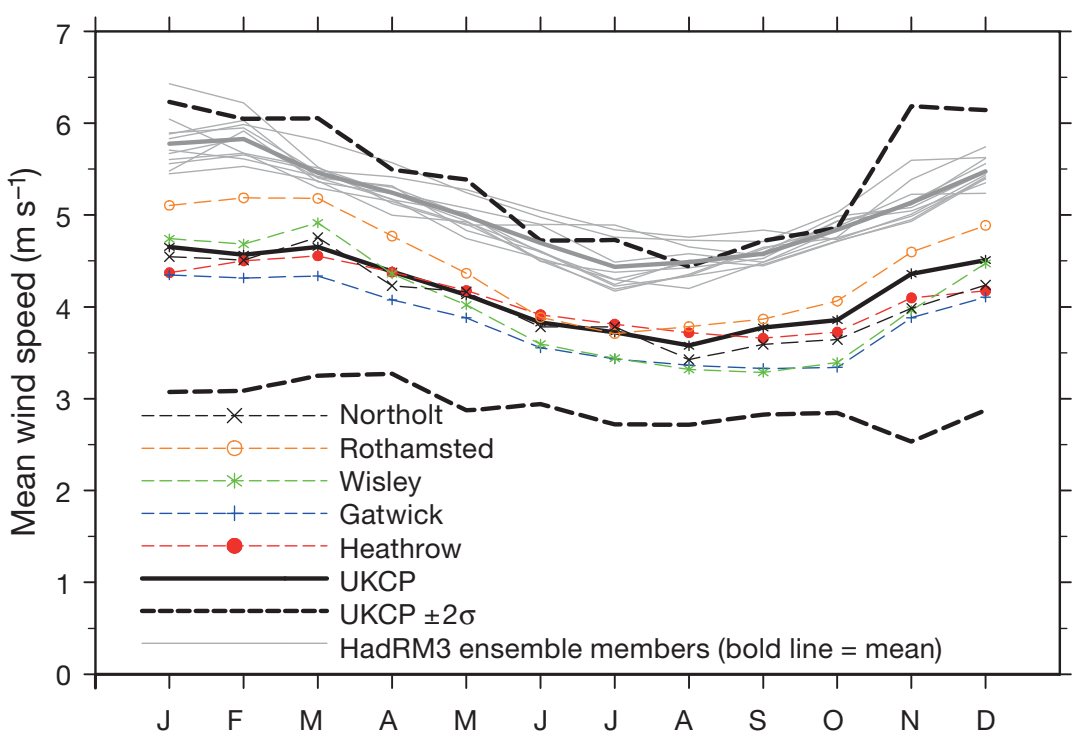

Fig. 2. Observed and RCM mean monthly wind speed. HadRM3 RCM ensemble (grey lines): 11 ensemble members for 1961-1990 for grid cell corresponding to South East London Resilience Zone (SELRZ) (ensemble mean in bold). UKCP (solid line): $5 \mathrm{~km}$ gridded monthly series averaged across the 23 grid cells comprising SELRZ, and \pm 2 SD of annual means (dashed lines). Locations (dashed lines with symbols): observed daily series in the region 
Heathrow grid cell differing from those for the SELRZ by $<3 \%$, suggesting it was valid to use the Heathrow series as the best available proxy for SELRZ mean daily wind speed. A comparison of the monthly distributions of daily mean wind speed for Heathrow and 1 ensemble member is shown in Fig. 3, indicating differences in the distributions and therefore that a simple correction based on monthly means (e.g. Fowler \& Kilsby 2007) would not be appropriate given the need to examine high wind speeds.

To reflect the differences in the distributions of RCM daily mean wind speed, a quantile correction method was adopted by calculating the 10th, 20th, 30th...90th, 95th and 99th percentiles for the Heathrow time series and for each of the RCM ensemble members' BSL simulations. The mean of all daily values falling within bins bound by each quantile were calculated on a monthly basis and used to determine quantile correction factors for each ensemble member. These were evaluated as the ratio of the monthly mean observed wind speed to the monthly mean wind speed for each ensemble member for each quantile bin. These factors were then used to scale the simulated BSL daily wind speed values for the corresponding month and quantile bins. Seasonal differences in the variation of these correction factors across quantiles were shown by Blenkinsop et al. (2010b), which may be attributable to biases arising from different physical mechanisms in the RCM at different times of the year.
As a result of this procedure, the quantile corrected monthly mean wind speeds for each RCM ensemble member reproduce those of the observed Heathrow series over the period 1961-1990, and the monthly distributions of daily mean wind speed are also more accurately reproduced (Fig. 3, green line). Assuming the same biases to be present in the model simulations throughout the future simulations, the same quantile correction factors may be applied to the future RCM daily mean wind speed simulations.

To examine the effect of this correction on the simulation of extreme wind speeds, 2 different measures were examined for the uncorrected and corrected RCM daily mean wind speeds and compared with observations: monthly 90th percentile of daily mean wind speed values ( $V_{\text {D90 }}$ ) and annual maximum daily mean wind speed. Fig. 4a indicates that after quantile correction the RCM ensemble simulations more closely reflect the observations, which lie within the corrected ensemble range, though these extremes are slightly underestimated in winter months. Similarly, the distributions of corrected ensemble annual maxima more closely represent those of the observations (Fig. 4b,c). There is a small $(<5 \%)$ overestimation of these events after correction due to the relative coarseness of the quantiles, and thus biases remain in the extreme tails of the distribution. This demonstrates the need for a detailed investigation of appropriate methods for bias correction and downscaling of extreme wind speeds that can be readily
Fig. 3. Comparison of observed (OBS) distributions of mean daily wind speed for selected months with ensemble member uncorrected (red line) and quantile corrected $(\mathrm{QC}$; green line) HadRM3q0 for baseline period
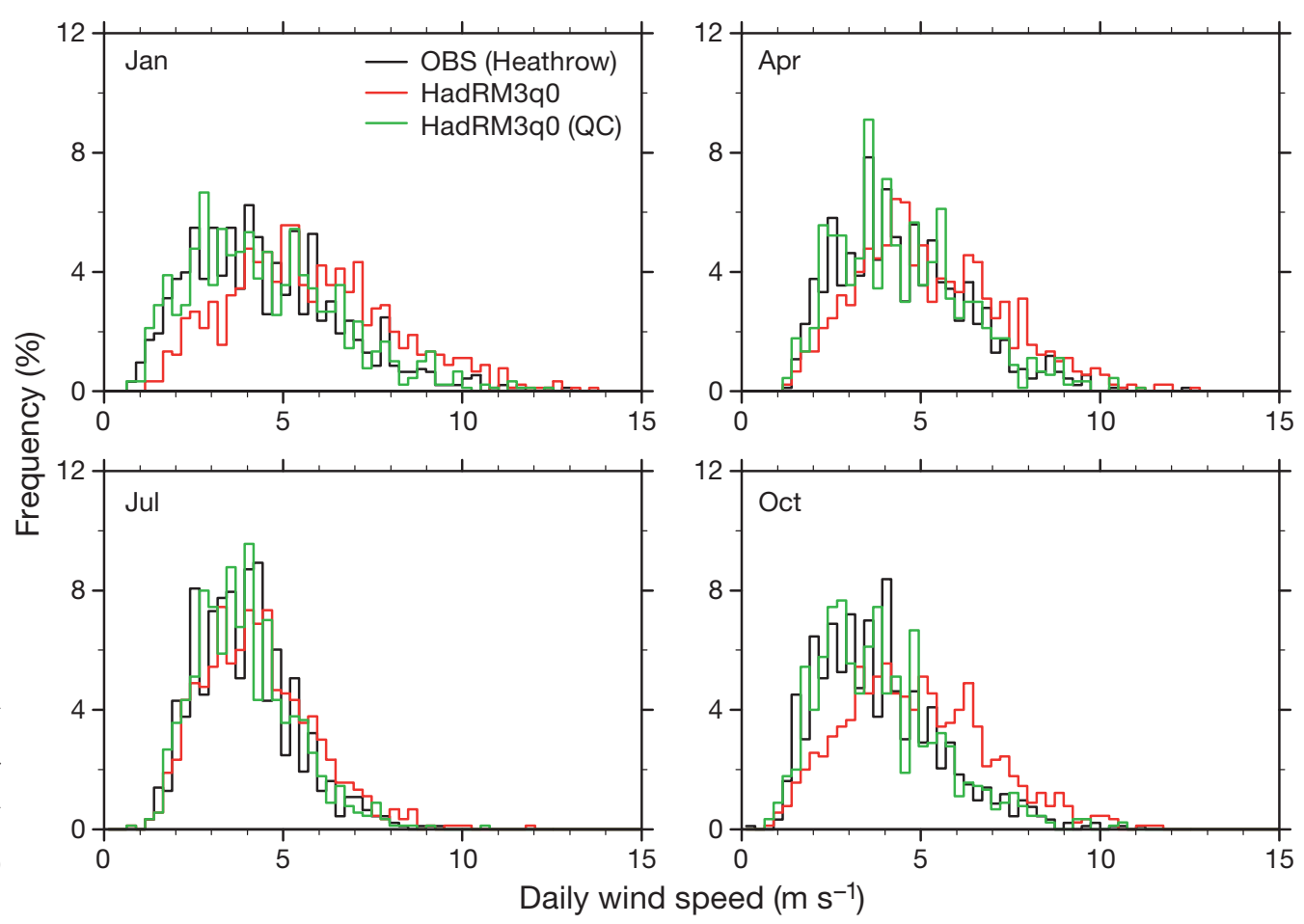

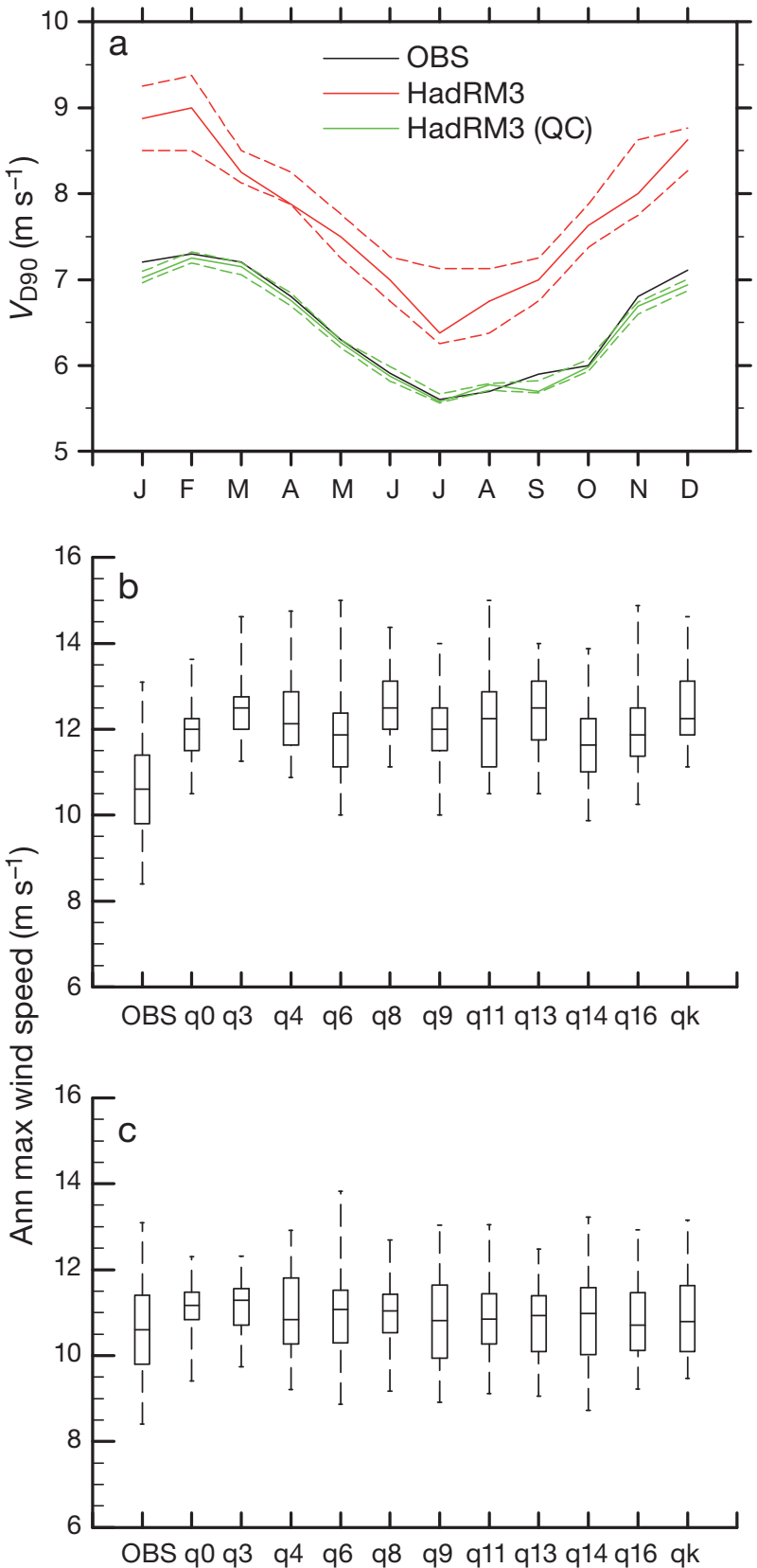

Fig. 4. (a) Monthly observed (OBS) and RCM 90th percentile mean daily wind speed values $\left(V_{\mathrm{D} 90}\right)$ for 1961-1990. Results are presented for raw and quantile corrected (QC) RCM output. Solid lines: ensemble median; upper and lower dashed lines: ensemble members ranked 2nd and 10th respectively. Boxplots: annual maximum (Ann max) mean daily wind speeds for (b) raw and (c) QC RCM outputs for baseline period (q0-qk) compared with OBS. Boxplot central horizontal line: median of 30 annual maxima; boxes: interquartile range; whiskers: extreme values

applied to an ensemble RCM experiment. Nonetheless, the method provides a more realistic representation of the events considered in the CREW project than is available directly from the RCM simulations.

\subsection{Downscaling methodology}

The wind variables identified as relevant hazards in the CREW project were the maximum hourly mean wind speed $\left(V_{\mathrm{H}}\right)$ and the hourly maximum 3 second gust wind speed $\left(V_{\mathrm{G}}\right)$. Temporal downscaling from $V_{\mathrm{D}}$ is achieved by applying empirically-derived factors based upon the relationship between daily mean and sub-daily wind speeds. This process is based on the assumption that changes in the former can be used to model changes in the latter and is regularly used in determining wind speed at point locations for estimating structural loading on proposed new buildings (Cook 1990). It is here applied for the first time on a regional basis and using ensemble climate model simulations. This approach is based on the accumulation of previous research and has been adopted within the UK code of practice for building design and the UK National Annex of the Eurocode. Similar gust factors are used elsewhere in Europe, e.g. gust correction factors based on land-use classification devised by Wieringa (1986).

Both $V_{\mathrm{H}}$ and $V_{\mathrm{G}}$ may be estimated from the daily mean wind speed $\left(V_{\mathrm{D}}\right)$ as follows:

and

$$
\mathrm{V}_{\mathrm{H}_{i}}=K_{1} K_{2_{i}} V_{\mathrm{D}}
$$

$$
\mathrm{V}_{\mathrm{G}_{i}}=K_{1} K_{3_{i}} V_{\mathrm{D}}
$$

where $i$ refers to individual $1 \mathrm{~km}$ grid squares based on the standard Ordnance Survey (OS) grid system. The $1 \mathrm{~km}$ resolution is used as the finest feasible resolution at which the topographical parameters used to calculate the values of $K_{2}$ and $K_{3}$ can be estimated and we assume that there is equivalence between this resolution and the station scale to which the RCM $V_{\mathrm{D}}$ data has been corrected.

$K_{1}$ is a correction factor that relates the hourly maximum to the daily mean of the time series, and $K_{2}$ relates these hourly maximum values at the reference position to those at the centre of each grid square, allowing for changes in altitude, roughness and topography. The factor $K_{3}$, in conjunction with $K_{1}$, relates the $V_{\mathrm{G}}$ values at the centre of each grid square to $V_{\mathrm{D}^{\prime}}$ again allowing for altitude, roughness and topography. It should be noted that these equations are for synoptic winds and separate correction factors are required for convective winds. However, as the latter tend to be of relatively low speed and therefore not relevant to this study, this distinction was unnecessary.

The factor $K_{1}$ was derived from the Heathrow Airport hourly wind speed MIDAS dataset for which homogeneous data was available for the period 
1961-1990, by evaluating the average ratio of the maximum hourly wind speeds to daily mean wind speeds. Data were only used when the wind direction was from the south west quadrant and with a daily mean wind speed $>5 \mathrm{~m} \mathrm{~s}^{-1}$. The south westerly direction was used because it is the prevailing direction for most strong winds whilst winds $<5 \mathrm{~m} \mathrm{~s}^{-1}$ are unlikely to present a hazard and therefore not considered relevant for the derivation of correction factors. A running $24 \mathrm{~h}$ mean wind speed was formed, and the ratio of the maximum hourly value to the running mean was calculated. From this, the cumulative probability distribution of the data was determined (Fig. 5a) from which appropriate values of $K_{1}$ may be estimated. Fig. 5a demonstrates that a range of possible values
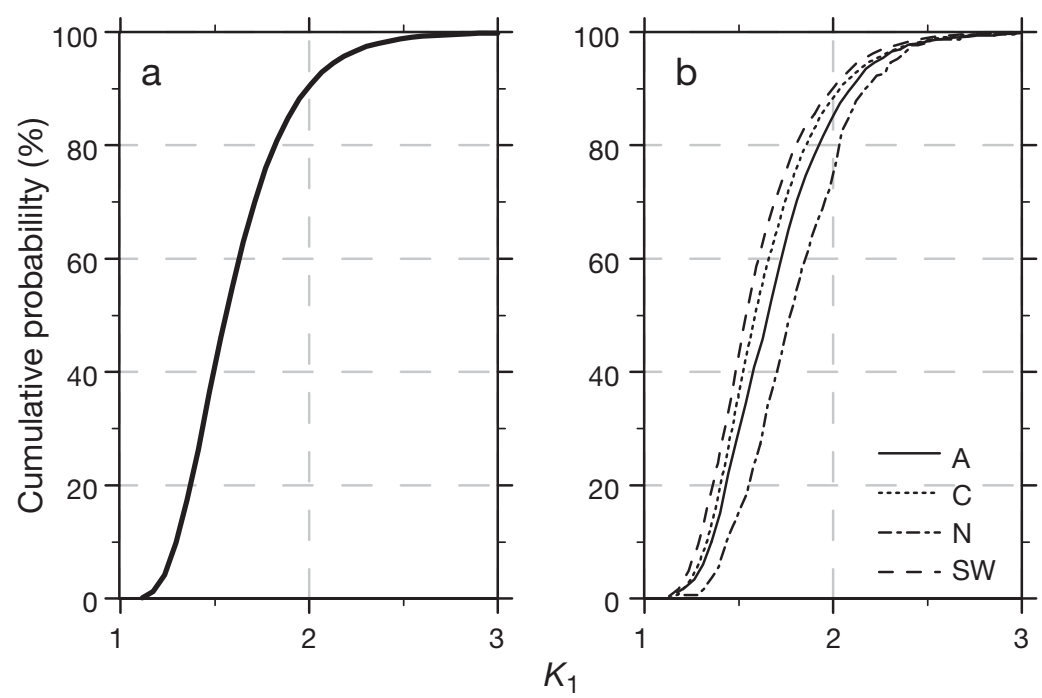

Fig. 5. Cumulative probabilities for ratios of maximum hourly mean wind speed to running $24 \mathrm{~h}$ mean wind speed $\left(K_{1}\right)$ at Heathrow (a) for all days when wind is from the south west quadrant and (b) further subdivided by Lamb Weather Type for anticyclonic (A), cyclonic (C), northerly (N) and south westerly (SW) types of 1 indicates a consistent wind speed over the $24 \mathrm{~h}$ period whilst higher values indicate that the maximum hourly wind speed exceeds the $24 \mathrm{~h}$ mean. The estimation of $K_{1}$ from Fig. 5a will clearly have an effect on the determination of $V_{\mathrm{H}}$ and $V_{\mathrm{G}}$. To investigate whether uncertainty in the estimation of $K_{1}$ could be reduced, the dependency of the form of Fig. 5a on different circulation regimes was considered. The distributions of $K_{1}$ were therefore calculated for different Lamb Weather Types to classify the daily circulation ${ }^{4}$. This indicated that whilst slightly different distributions of $K_{1}$ are obtained for different weather types, none of these demonstrated substantially reduced ranges of $K_{1}$ (Fig. 5b). The distribution shown in Fig. 5a was therefore selected and the 90th percentile used in accordance with the thresholds adopted in Section 4.2.

Both $K_{2}$ and $K_{3}$ depend upon the classification of the terrain. To determine each of these values, the land use both within the SELRZ and for the $20 \mathrm{~km}$ fetch to the south west was examined, as the terrain characteristics of this extended area have an effect upon the wind speeds within the SELRZ. A $1 \mathrm{~km}$ square grid based on the standard OS grid system was overlaid on the SELRZ (Ordnance Survey 2009a). For each grid square, a terrain value was assigned by comparing the 1:250 000 OS Landranger map (Ord-

${ }^{4}$ The daily Lamb Weather Type time series provided by the Climatic Research Unit may be downloaded from www. cru.uea.ac.uk/cru/data/lwt/ nance Survey 2009b) with satellite images available on Google Earth ${ }^{5}$. Where multiple land uses were apparent in any one grid square, the percentage area of each terrain type was calculated and the grid was assigned to the dominant land use type.

The categories used for assigning roughness length $\left(z_{0}\right)$ to each terrain type were based on BSI (2005) and are shown in Table 1. Roughness length gives a measure of the effect of obstacles on the wind profile and is dependent on the surface area that obstacles present to the wind relative to the ground area they occupy. Due to the characteristics of the terrain across the SELRZ, the need for an intermediate value between the terrain categories 2 and 3 was identified $_{i}$ the categorisation was therefore modified by an additional category of 2.5 with a roughness length of $0.1 \mathrm{~m}$.

To aid in the identification of the 'edge of town' needed to correctly calculate $K_{2}$ and $K_{3}$, a range of running averages of $z_{0}$ were calculated along diagonal (south west-north east) transects across the study area and the fetch. The spatially averaged values of roughness decrease from north east to south west along the transects as the terrain changes from urban to more rural areas. The 'edge of town' was taken as the point at which the spatially averaged values of $z_{0}$ decreased to $0.2 \mathrm{~m}$.

\footnotetext{
56oole (2009) Google Earth available from http://earth. google.co.uk/ (accessed 15 June 2009)
} 
Table 1. Terrain category definitions (modified from BSI 2005, p. 20)

\begin{tabular}{|c|c|c|}
\hline $\begin{array}{l}\text { Terrain } \\
\text { number }\end{array}$ & Terrain category & $\begin{array}{l}\text { Roughness } \\
\text { ength } z_{0}(\mathrm{~m})\end{array}$ \\
\hline 0 & $\begin{array}{l}\text { Sea or coastal areas exposed to the } \\
\text { sea }\end{array}$ & 0.003 \\
\hline 1 & $\begin{array}{l}\text { Lakes or flat and horizontal areas } \\
\text { with negligible vegetation and } \\
\text { without obstacles }\end{array}$ & 0.01 \\
\hline 2 & $\begin{array}{l}70 \% \text { of areas with low vegetation } \\
\text { such as grass and isolated obstacles } \\
\text { (trees, buildings) with separations of } \\
\text { at least } 20 \text { obstacle heights (height of } \\
\text { the average 'roughness element', i.e. } \\
\text { trees, bushes, houses, etc.) }\end{array}$ & 0.05 \\
\hline 2.5 & $\begin{array}{l}30 \% \text { or more of area Category } 2, \text { with } \\
\text { the rest of area Category } 3 \text { (with a } \\
\text { minimum of } 30 \% \text { of area Category } 3 \text { ) }\end{array}$ & h \\
\hline 3 & $\begin{array}{l}70 \% \text { of area with regular cover of } \\
\text { vegetation or buildings or with iso- } \\
\text { lated obstacles with separations of } \\
\text { maximum } 20 \text { obstacle heights (such } \\
\text { as villages, suburban terrain, } \\
\text { permanent forest) }\end{array}$ & 0.3 \\
\hline 4 & $\begin{array}{l}\text { Area in which at least } 15 \% \text { of the } \\
\text { surface is covered with buildings and } \\
\text { their average height exceeds } 15 \mathrm{~m}\end{array}$ & 1.0 \\
\hline
\end{tabular}

As an upward slope in the direction of the wind accelerates the wind speed, a topographical factor, $S_{\mathrm{TOP}}$ is required to reflect this increase in wind speed. Ordnance Survey (2009c) topographical data for the region was used to determine the altitude above sea level $(A)$ at the centre of each $1 \mathrm{~km}$ grid square. From these data it was also possible to calculate those areas where the southwest to northeast slope (difference in height between squares $\div 1000$ ) exceeded 0.05, which was equivalent to a $50 \mathrm{~m}$ difference in height between the centres of adjacent grid squares; for these squares a value $S_{\mathrm{TOP}}$ was required. Only upward slopes in the direction of the prevailing wind affect $S_{\mathrm{TOP}}$, which is assumed to be zero for flat or downward slopes. Where the slope exceeded 0.05 the factor was calculated as:

$$
S_{\text {TOP }}=2 \times \text { slope }
$$

The $K_{2}$ factor was then obtained from the equations in Cook (1990), which was compatible with British Standard BS 6399, the precursor to the current UK code and the Eurocode National Annex, namely - in 'country' terrain:

$$
K_{2 i}=\left(1+0.001 A_{i}\right) S_{\mathrm{SC}}\left(1+S_{\mathrm{TOP} i}\right)
$$

in 'town' terrain:

$$
K_{2 i}=\left(1+0.001 A_{i}\right) S_{\mathrm{SC}}\left(1+S_{\mathrm{TOP} i}\right) S_{\mathrm{CT}}
$$

where $A$ is the grid cell altitude, and values for the fetch factor $\left(S_{\mathrm{SC}}\right)$ and adjustment fetch factor $\left(S_{\mathrm{CT}}\right)$ were obtained from Appendix $\mathrm{K}$ in, Tables 1 and 2 in Cook (1990, p. 517). All values used for $K_{2}$ were derived for an effective height of $10 \mathrm{~m}$.

The $K_{3}$ factor was found from similar expressions to those used for $\mathrm{K}_{2}$ - in 'country' terrain:

$$
K_{3 i}=\left(1+0.001 A_{i}\right) S_{\mathrm{SC}}\left(1+g_{\mathrm{GUST}} S_{\mathrm{TSC}}+S_{\mathrm{TOP}_{i}}\right)
$$

in 'town' terrain:

$$
\begin{aligned}
& K_{3 i}= \\
& \left(1+0.001 A_{i}\right) S_{\mathrm{SC}}\left(1+g_{\mathrm{GUST}} S_{\mathrm{TSC}} S_{\mathrm{TCT}}+S_{\mathrm{TOP}_{i}}\right) S_{\mathrm{CT}}
\end{aligned}
$$

For a 3 second gust, the gust peak factor $\left(g_{\mathrm{GUST}}\right)$ was taken as having the value of 3.0 (Cook 1990). The turbulence factor $\left(S_{\mathrm{TSC}}\right)$ and the adjustment turbulence factor $\left(S_{\mathrm{TCT}}\right)$ were again found from the relevant tables for an effective height of $10 \mathrm{~m}$ (in Cook 1990, p. 517). The presence of many buildings is taken into account to some extent in the contribution of the roughness length to the determination of the factors $S_{\mathrm{CT}}$ and $\mathrm{S}_{\mathrm{TCT}}$ i however, the presence of very tall buildings identified in some parts of the SELRZ may lead to localised increases in wind speed that cannot be fully considered in this work.

Finally, to downscale $V_{\mathrm{D}}$ from the RCM scale (25 $\mathrm{km}$ ) to the $1 \mathrm{~km}$ scale, for $V_{\mathrm{H}}$ and $V_{\mathrm{G}}$, the relevant $K$ factors (Eqs. $1 \& 2$ ) were applied to derive a pair of downscaling factors for each grid cell. The downscaling factors for $V_{\mathrm{G}}$ are shown in Fig. 6 and are applied to the quantile corrected daily mean wind speed from each ensemble member to generate downscaled series at $1 \mathrm{~km}$ resolution across the SELRZ.

\section{RESULTS}

\subsection{Projected changes in mean daily wind speed}

Before examining projected changes in hazards related to EWEs using the downscaled projections, changes in the mean climatology projected directly by the RCMs were examined. Mean monthly values of quantile-corrected daily mean wind speed for SCN20 and SCN50 were calculated for each ensemble member and the range was compared with the observed means (OBS) for the Heathrow series (Fig. 7). For this purpose, and hereafter, the ensemble range refers to that defined by the 2nd and 10th ranked values in the ensemble. This range was selected for consistency with other hazards examined in the 


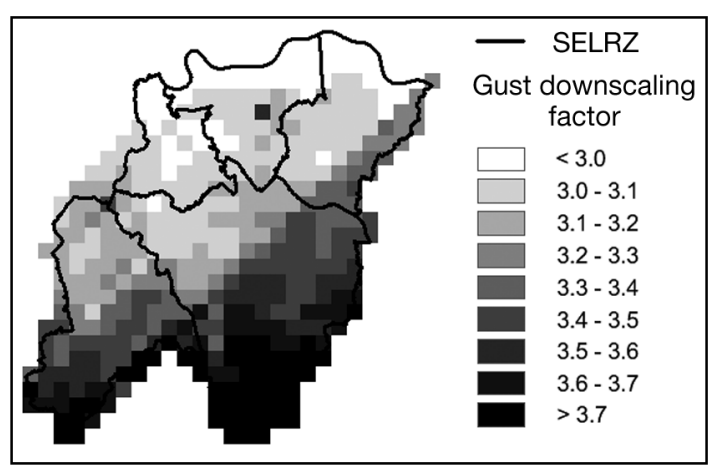

Fig. 6. Maximum 3 second gust wind speed $\left(V_{\mathrm{G}}\right)$ downscaling factors $\left(K_{1} K_{3}, 90\right.$ th percentile) over South East London Resilience Zone (SELRZ). Corresponding factors were also generated for maximum hourly mean wind speed $\left(V_{\mathrm{H}}\right)$

CREW project for which the 10th and 90th percentiles are being evaluated from probabilistic projections provided by UKCP09. They also approximate the definitions adopted by UKCP09, i.e. users can identify the levels of hazard that are 'very likely' to be exceeded, a 'central estimate' and 'very unlikely' to be exceeded. The Heathrow series was used for comparison, although, as noted above, after quan- tile correction the monthly BSL means for each ensemble member match those of the observed series. Overall, there is little projected change in $V_{\mathrm{D}}$ for SCN20 (Fig. 7a), and even for SCN50 (Fig. 7b) there are only small projected decreases in late winter/ early spring and in early autumn and small increases between November and January. Sampling variability for the observed monthly means (OBS) is shown by the $95 \%$ confidence intervals obtained by applying a bootstrap procedure (Efron \& Gong 1983) using random resampling with replacement to obtain a distribution of 10000 thirty-year means for each month. To derive a $(1-\alpha) \%$ confidence interval, the value of this distribution at the largest and smallest $n_{B} \times \alpha / 2$ of the $\mathrm{n}_{\mathrm{B}}$ bootstrap estimates is obtained (Efron \& Tibshirani 1993). For both SCN20 and SCN50, the range of projected future mean daily wind speeds is not significantly different to that of BSL. For SCN50, Fig. 7C shows that for most individual ensemble members the projected change is within the $95 \%$ confidence limits of the observed monthly means throughout the year. Furthermore, the 11 individual ensemble members show no consistent pattern of seasonal change although most project an increase between Novem-
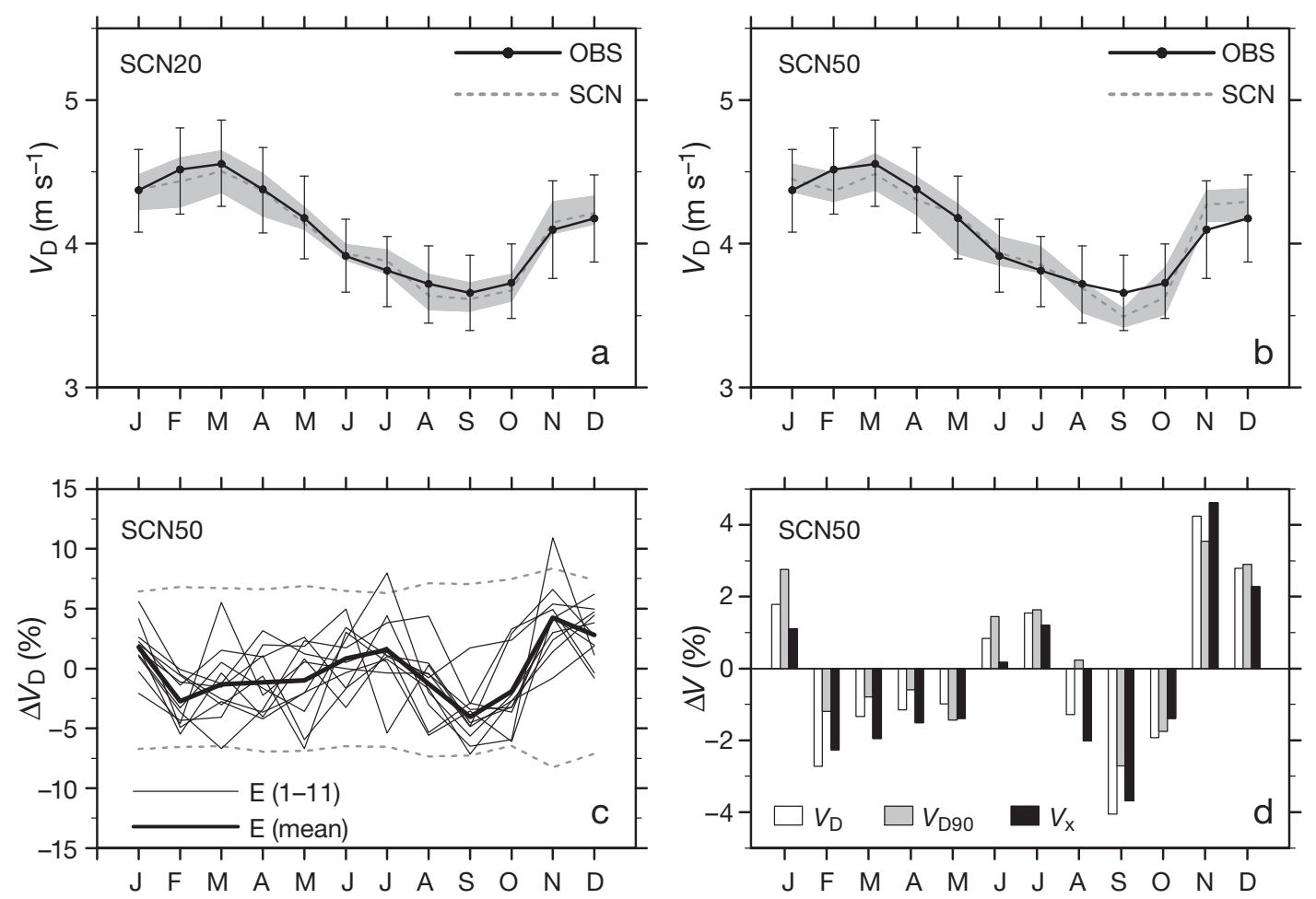

Fig. 7. Projected monthly mean daily wind speed $\left(V_{\mathrm{D}}\right)$ after quantile correction for (a) SCN20 and (b) SCN50. Observed (OBS) Heathrow dataset is shown with $95 \%$ CI derived from a bootstrapping procedure. Shaded area: projected future ensemble range as defined in text. Bootstrapped CIs for future means are not shown for clarity. (c) Percentage change projected by 11 en-

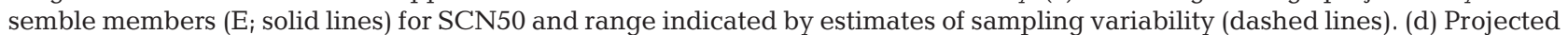
change in ensemble mean for $V_{\mathrm{D}}$, 90th percentile of mean wind speed ( $\left.V_{\mathrm{D} 90}\right)$ and RCM maximum wind speed ( $\left.V_{\mathrm{X}}\right)$ for SCN50 
ber and January and a decrease in the periods August to October and February to April. As the hazards of interest are related to extreme events, ensemble changes in the 90th percentile of the mean daily wind speed $\left(V_{\mathrm{D} 90}\right)$ and in the maximum daily wind speed $\left(V_{\mathrm{X}}\right)$ also available from the RCM are shown in Fig. $7 d$. This indicates that changes in extremes are of the same order of magnitude as those in $V_{\mathrm{D}^{\prime}}$ though future increases in $V_{\mathrm{D} 90}$ tend to be slightly greater than those for $V_{\mathrm{D}}$ whilst decreases tend to be smaller. However, the same pattern is not observed for $V_{\mathrm{X}}$, which is only projected to have the greatest increases in November.

The projected future change was also considered within the context of internal model variability over the baseline period. As the quantile correction method results in identical monthly means for all ensemble members that match the observations, it was necessary to use the uncorrected RCM output to make this assessment. Fig. 8 therefore shows the ensemble range for both BSL and SCN simulations, the former indicating the uncertainty in reproducing the BSL climate associated with RCM parameterisation. For both SCN20 and SCN50, most of the projected range in future mean wind speed is within the range of the BSL ensemble uncertainty, although for SCN50 during autumn (SON) $\sim 50 \%$ of the future range lies outside the BSL ensemble uncertainty range.

In summary, future changes in monthly averaged mean daily and extreme wind speed across the SELRZ are relatively small, typically $< \pm 5 \%$ for SCN50, and are not significantly different to those for BSL. Further, the uncertainty associated with RCM baseline parameterisation tends to incorporate most of the range of future projections.

\subsection{Projected changes in user-centred hazard thresholds from downscaled RCM ensemble wind speed projections}

Previous studies of projected wind speeds have tended to adopt either a standard climatological approach of examining percentiles or used the analysis of return periods, e.g. Brown et al. (2008). The CREW project is taking a user-centred approach, providing climate change information based on the needs of a range of stakeholders. The need for windrelated hazard projections is met through the application of critical threshold values in relation to the effects of the wind on human health/well-being and infrastructure. For southern England, Cook (1985) indicated that maximum gust speeds of $35 \mathrm{~m} \mathrm{~s}^{-1}$ with
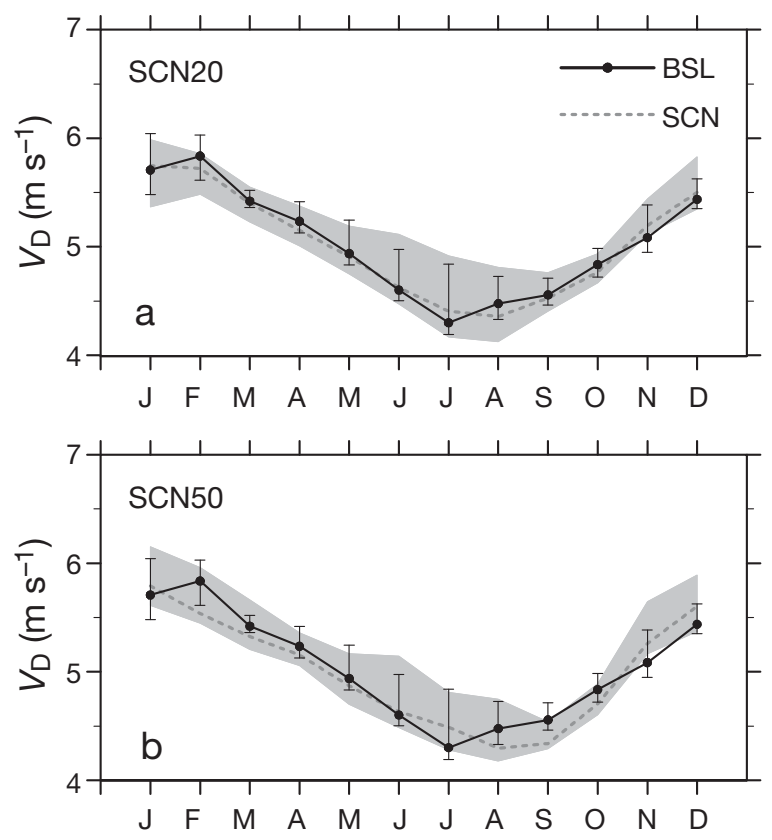

Fig. 8. Projected monthly mean daily wind speed $\left(V_{\mathrm{D}}\right)$ before quantile correction for (a) SCN20 and (b) SCN50 compared to baseline (BSL) period. Lines: central estimate (median) of the 11-member ensemble; error bars and shaded area: ensemble range as defined in Section 4.1 for BSL and SCN respectively

the $K_{1}$ 90th cumulative percentile (as derived from Fig. 5) give a threshold for likely building damage. There is also a wide range of thresholds cited in the literature relating to pedestrian comfort/safety (Jordan et al. 2008). It has been noted that pedestrians begin to feel discomfort when hourly mean wind speeds exceed $5 \mathrm{~m} \mathrm{~s}^{-1}$ (Metje et al. 2008), whilst speeds in excess of $15 \mathrm{~m} \mathrm{~s}^{-1}$ are deemed dangerous, though it is generally agreed that gusts are the most critical factor affecting pedestrians (Stathopoulos 2006, Jordan et al. 2008). We therefore adopt the threshold of gust speeds of $20 \mathrm{~m} \mathrm{~s}^{-1}$ as representing dangerous conditions for pedestrians (Hunt et al. 1976, Bottema 1992). To demonstrate how the methodology may be applied, results are presented which portray the climate modelling uncertainty in the RCM ensemble for these thresholds; however, for brevity only results for SCN50 are shown.

\subsubsection{Frequency and magnitude of extreme events: projected risk of damage to buildings}

For each grid cell and each RCM ensemble member the number of days on which the condition $V_{\mathrm{G}}>$ $35 \mathrm{~m} \mathrm{~s}^{-1}$ was satisfied was evaluated for BSL (using the median of the 11 ensemble members for each 
grid cell) and SCN50, and the average annual number of exceedances was calculated for each. The appropriate downscaling factor was also applied to the observed mean daily wind speed series (OBS) for comparison with BSL. Uncertainty ranges for future wind speed projections were presented by extracting for each grid cell a lower (LOW), central (CEN) and sponding to the 2 nd, 6th and 10th ranked values in the ensemble respectively. This approximates the UKCP09 nomenclature identified in Section 4.1 whereby the mapped projections may be described as 'very unlikely to be less than' for the LOW projection and 'very unlikely to be greater than' for the $\mathrm{HIGH}$ projection, whilst CEN indicates the 'central estimate'.

Fig. 9 indicates that the spatial distribution of exceedances for the simulated BSL closely matches that for OBS; the annual exceedance rate is over(under-)estimated for $\sim 27 \%$ (59\%) of grid cells but the magnitude of this error is $<0.2$ events $\mathrm{yr}^{-1}$ ( 1 event per $5 \mathrm{yr}$ ) for $>80 \%$ of grid cells. These events occur at least once per yr in over $\sim 40 \%$ of grid cells, and over much of the area is less extreme than the annual maximum, so this threshold may not be severely affected by the biases considered in Fig. 4 . For SCN50 the central estimate indicates a relatively small increase from BSL; averaged over the whole SELRZ, mean annual exceedance increases from 1.3 to 1.4 events (CEN) but this ranges from a decrease to 1.2 events (LOW) to an increase to 1.6 events (HIGH). Although for CEN most grid cells are projected to experience an increase in the frequency of these events, they remain at $<1$ event $\mathrm{yr}^{-1}$ in the more upper (HIGH) estimate of future exceedances corre-

densely populated northern areas of Lewisham, Greenwich and Bexley. This spatial pattern reflects the fact that variations in gust speed inside and outside urban areas are taken into account through the use of different surface roughness and gust factors (Eqs. 4-7). The total proportion of the study area that is projected to experience at least 1 event $\mathrm{yr}^{-1}$ increases slightly from $\sim 44$ to $\sim 47 \%$, all in the south of Croydon and Bromley. The HIGH projection indicates an increase for all grid cells, although the area experiencing at least one such event per year increases only slightly to $48 \%$ and remains largely limited to central and southern parts of Croydon and Bromley. The LOW estimate, in contrast, projects reduced frequencies for $\sim 54 \%$ of grid cells with the proportion of the area projected to have at least 1 event $\mathrm{yr}^{-1}$ decreasing to $40 \%$.

To examine the change in the magnitude of hazardous events, the distribution of the downscaled 30-yr daily $V_{\mathrm{G}}$ series for both BSL and 2050 were examined and the 99th percentile $\left(V_{\mathrm{G} 99}\right)$ determined for each grid cell to indicate future changes in the magnitude of events of a given probability (Fig. 10). This represents events occurring on average 3 to 4 times $\mathrm{yr}^{-1}$.

For BSL, the magnitude of the $V_{\mathrm{G} 99}$ event exceeds the $35 \mathrm{~m} \mathrm{~s}^{-1}$ threshold over $6.9 \%$ of the SELRZ and demonstrates a strong agreement with OBS (average difference of $0.1 \%$ ). For SCN50 the increase in magnitude of $V_{\mathrm{G} 99}$ is between $<0.1 \%$ (LOW) and $1.5 \%(\mathrm{HIGH})$, and consequently the proportion of the SELRZ where $V_{\mathrm{G} 99}$ exceeds the threshold ranges from 6.9 (LOW) to $10.4 \%$ (HIGH) with CEN of $9.7 \%$. Fig. 10 indicates that multiple annual events exceed-

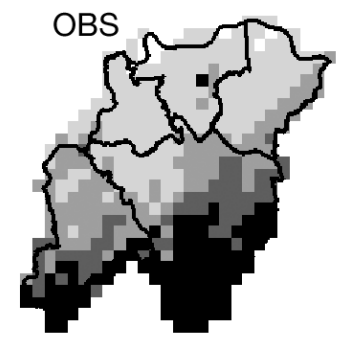

per year when maximum 3 second gust wind speed $\left(V_{\mathrm{G}}\right)>$ $35 \mathrm{~m} \mathrm{~s}^{-1}$ and potentially causes damage to the built environment. Data for baseline period (BSL), observed (OBS) and 2050s projection (SCN50). LOW, CEN and HIGH: 2nd, 6th and 10th ranked values for each grid cell, respectively. Scale: 5 quantiles for BSL simulation. SELRZ: South East London Resilience Zone
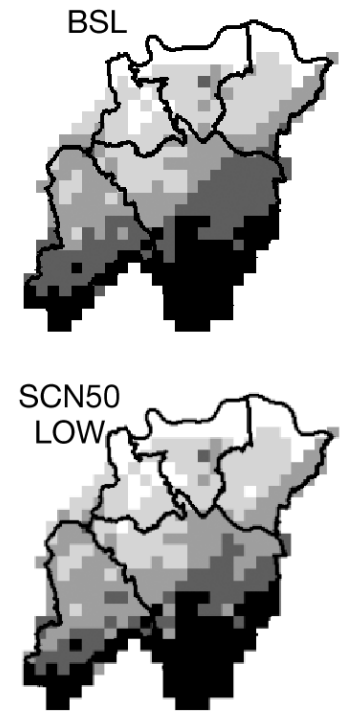

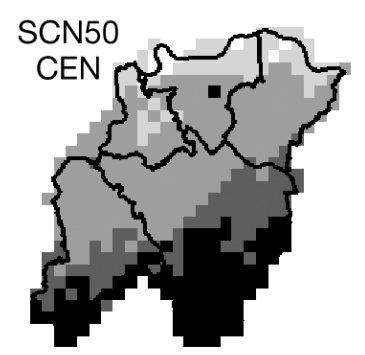

\section{SELRZ}

Average number of days per year with risk of damage to buildings $<0.22$ $0.22-0.42$

$0.42-1.33$

$1.33-1.99$ $>1.99$

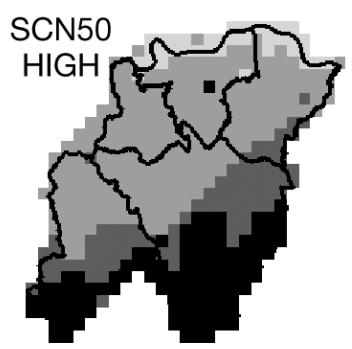



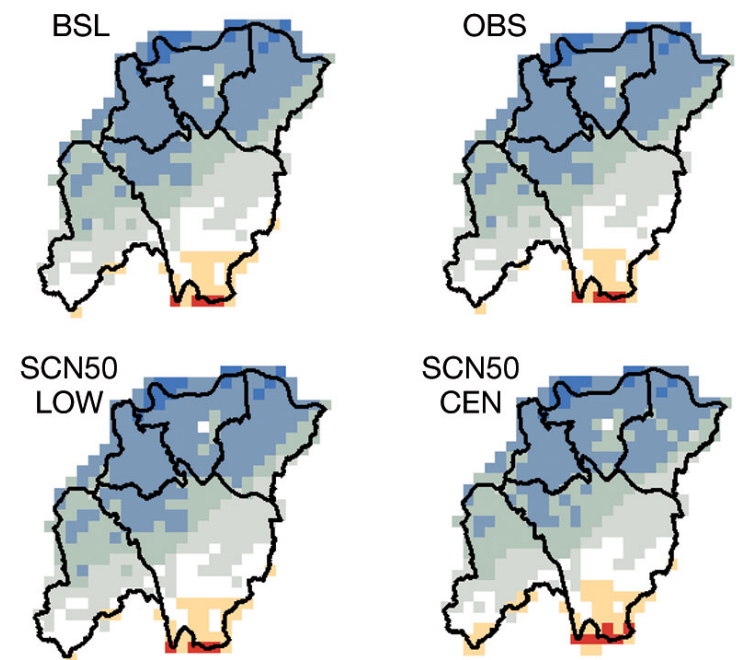
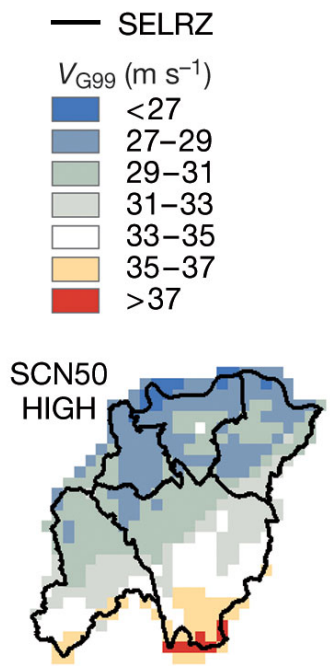

Fig. 10. Magnitude of 99th percentile daily $V_{\mathrm{G}}\left(V_{\mathrm{G} 99}\right)$ showing $V_{\mathrm{G} 99}$ range below (blue) and above (red) critical $35 \mathrm{~m} \mathrm{~s}^{-1}$ threshold. Results presented for BSL, OBS and SCN50 (LOW, CEN, HIGH). See Fig. 9 for abbreviations

ing this critical threshold are likely to be confined to southern Bromley and to a lesser extent southern Croydon. For the CEN projection there is relatively little change in the spatial distribution of $V_{\mathrm{G} 99}$ magnitudes, and even for HIGH the general increase in magnitudes does not manifest itself in a substantial increase in the area exposed to damaging events.

In summary, the ensemble suggests that it is likely that there will be a slight increase in the frequency of events potentially causing damage to buildings, though these events will remain relatively rare $(<1$ in 4 yr) for Greenwich, Lewisham, Bexley and northern Croydon. The magnitude of extreme events is also likely to increase, but again the projected change is small.

\subsubsection{Probability of extreme events: danger to pedestrians}

An alternative way in which hazard information may be presented to users is in the form of probabilities of events occurring. Fig. 11 presents current and future probabilities of daily events where $V_{\mathrm{G}}>20 \mathrm{~m} \mathrm{~s}^{-1}$, which have previously been identified as potentially dangerous to pedestrians in urban areas. This threshold is not measuring such an extreme part of the distribution as the annual maximum and so is unlikely to be so severely affected by
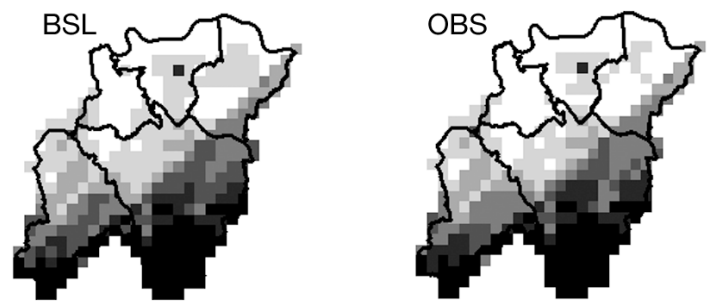

- SELRZ

Probability of danger to pedestrians

$\square<0.1$

$\square \quad 0.1-0.12$

$\square \quad 0.12-0.14$

$0.14-0.16$

$0.16-0.18$

$0.18-0.2$
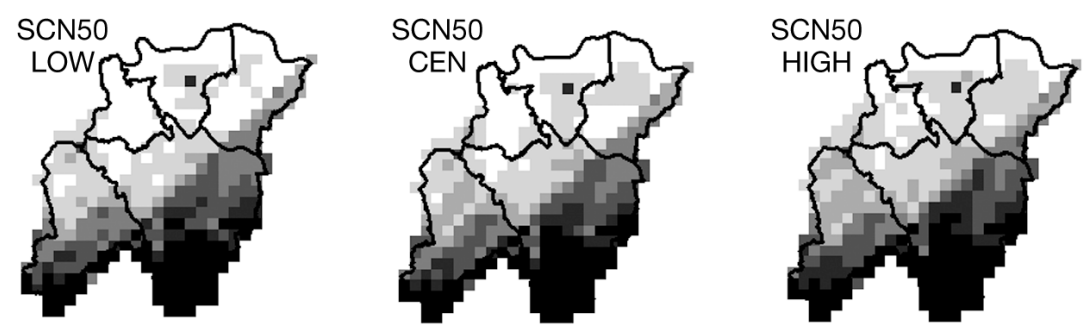

Fig. 11. Probability of a given day presenting a danger to pedestrians ( $V_{\mathrm{G}}>$ $20 \mathrm{~m} \mathrm{~s}^{-1}$ ). Results presented for BSL, OBS and SCN50 (LOW, CEN, HIGH). See Fig. 9 for abbreviations 
by users, for high resolution projections of future wind speeds for the UK under a changing climate. There is currently no provision of downscaled wind variables by the UKCP09 weather generator (Jones et al. 2009) and so there remains a mismatch between the needs of, for example, engineers, structural design practitioners and local planners and the current provision of wind projections. A methodology has been described which demonstrates how a standard engineering approach may be linked with climate bias correction or downscaling methodologies to provide user-relevant projections of current and future city-scale hazards. This was applied to a stateof-the-art 11-member perturbed physics RCM ensemble, to derive $1 \mathrm{~km}$ resolution projections of maximum wind gust and mean hourly wind speeds over south-east London for a baseline (1961-1990) and future (2020s and 2050s) climate using a medium emissions scenario. The 2-step method combines RCM quantile correction with an approach previously used for determining wind speed at point locations to estimate structural loading on proposed urban developments (Cook 1990), adapted to the study area and applied over the region at a resolution of $1 \mathrm{~km}$. It is demonstrated how the application of relevant critical thresholds may be used to assess current and future exposure to specific community hazards and how quantified estimates of climate modelling uncertainty may be presented in an accessible format.

Changes in mean daily wind speed by the 2050s are likely to be small and are not significantly different to those for BSL. With regard to hazards, the central estimate of the RCM ensemble suggests a small increase in the frequency of events that pose a risk of damage to buildings from an average of 1.3 to 1.4 events $\mathrm{yr}^{-1}$ rising to 1.6 for the HIGH estimate projection. The relatively small change across the SELRZ is related to the fact that the projected increases in extreme wind speeds are relatively small and so the $35 \mathrm{~m} \mathrm{~s}^{-1}$ threshold is not exceeded more frequently across much of the area. It should be reiterated, however, that tall buildings which may produce localized wind effects are not taken into account in this study and that complex urban morphology in cities means that variation in gusts can be very large, and thus local scale damage may occur at gusts distributed around the $35 \mathrm{~m} \mathrm{~s}^{-1}$ value. Such effects can only be accurately assessed through the use of local scale wind tunnel or computational wind engineering methods (e.g. Stathopoulos 2006). However, the locations of tall buildings in the SELRZ have been recorded and may be mapped as a layer on the above maps to allow users to identify potentially vulnerable locations.
Relatively little change is projected in the probability of an event considered potentially dangerous to pedestrians, even considering the HIGH projection. However, again it should be noted that the use of thresholds does not present a definitive assessment of vulnerability, as different groups such as the elderly may be susceptible to danger at lower gust speeds (Hunt et al. 1976). Overall, qualitatively, the relatively small changes presented here are consistent with the conclusions set out by City of London (2010) for the 2080s indicating that evidence for changes in windstorm hazards is poor and that the hazard rating associated with these events in the Community Risk Register remains as 'medium'.

It should be noted that the uncertainties considered here are not comprehensive. Firstly, the RCM ensemble experiment only uses one future emissions scenario (A1B), and therefore the projected range of hazard may be larger than that considered here. However, a multi-model ensemble examined by Kjellström et al. (2011) indicated that changes in wind speed were relatively insensitive to emissions scenario. Secondly, the ensemble does not reflect uncertainty associated with internal model structure as it is based on a single RCM and driving GCM. GCM selection has been shown to contribute a significant source of uncertainty in dynamically downscaled projections of wind speed and gusts (e.g. Schwierz et al. 2010, Kjellström et al. 2011, Nikulin et al. 2011) including for south east England (Brown et al. 2009). This is due to the fact that simulations of wind speed obtained from RCMs are normally related to the representation of large-scale circulation by GCMs (Räisänen et al. 2004). However, although the UKCP09 probabilistic projections (Murphy et al. 2010, Sexton \& Murphy 2010) incorporate additional IPCC GCM simulations and so provide a more complete quantification of uncertainty in climate projections, they do not currently provide the high spatial and temporal resolution wind speed data required. It is worth noting nevertheless that the changes in mean wind speed presented here for SCN50 are consistent with those indicated by the UKCP09 probabilistic projections.

One source of current modelling uncertainties is related to simulations of North Atlantic storm tracks. The GCM perturbed physics ensemble used by UKCP09 to provide boundary conditions for the RCM simulations has been noted to better simulate these storm tracks than the CMIP3 multi model ensemble (Brown et al. 2009, Murphy et al. 2010) but still exhibits a slight underestimation of mean intensity at UK longitudes. It also features a slight southern 
displacement relative to observations (Jenkins et al. 2009). The UKCP09 ensemble RCM simulations are noted to replicate synoptic scale patterns of error in the driving global simulations (Brown et al. 2009), which in turn project that by the 2080s there will be a slight weakening of the intensity and southward shift of storm tracks. In contrast, a multi-model ensemble projects less change in position and a wider range of (generally positive) changes in strength (Jenkins et al. 2009, Murphy et al. 2010). The IPCC 4AR (Meehl et al. 2007) reports a general tendency for a poleward shift in northern hemisphere storm tracks, though this is not so evident in a GCM ensemble examined by Ulbrich et al. (2008). A review of modelling studies with regards to extra-tropical cyclones is provided by Ulbrich et al. (2009) who describe a mixed picture from modelling experiments, but indicate that the frequency of winter cyclones will decrease in the northern hemisphere, though most models suggest an increase in the number of intense cyclones affecting the British Isles. Jenkins et al. (2009, p. 39) summarise the state of current knowledge by stating that 'robust projections of changes in storm track are not yet possible'. Uncertainties associated with such model representations of mid-latitude storms have been attributable to the use of different datasets and tracking algorithms, model resolution, differences in projected polar surface and upper tropical tropospheric warming, and changes in the North Atlantic Meridional Overturning Circulation (Ulbrich et al. 2009, Bader et al. 2011). The importance of a fully resolved stratosphere in coupled ocean-tropospherestratosphere GCMs has been highlighted (Huebener et al. 2007) and a well resolved stratosphere has been demonstrated to be important in the modelling of climate variability and prediction for the North Atlantic and European (NAE) region due to its importance in determining characteristics of the ENSO-NAE teleconnection (Cagnazzo \& Manzini 2009). Scaife et al. (2012) recently reported that improved modelling of the stratosphere in an ensemble of GCMs projected a consistent southward shift of storm tracks and an increase in mid-latitude storminess compared with an ensemble of GCMs with poor stratospheric resolution. However, Brown et al. (2009) indicate from the analysis on one UKCP09 ensemble member that patterns of wind speed bias found in the RCMs cannot be explained by biases in the large scale circulation inherited from the driving GCM simulations and must therefore be associated with problems in the simulation of regional boundary layer effects. Although it is reassuring that the ensemble reproduces the main annual variation in mean wind speed over this area, until such issues in climate models have been resolved, local scale projections of extreme wind speeds will remain uncertain. A detailed assessment will require the analysis of model simulations generated for the IPCC Fifth Assessment Report that have implemented such improvements (Sexton \& Murphy 2010).

Uncertainty in regional climate change projections also arises from the use of statistical downscaling methodologies. These make the general assumption that biases in climate models as well as inter-variable relationships observed in the current climate, such as that used here in the derivation of $K_{1}$, are preserved in the future. Threshold exceedance was found to be sensitive to the estimated value of $K_{1}$ (not shown), so any future changes in this relationship may produce significant differences in future hazard projections. This needs to be acknowledged not only when applying this method to climate change applications but also in the assessment of current hazards by using a sufficiently long period of observed data to estimate $K_{1}$ robustly. Here, a complete assessment of uncertainties would acknowledge the distribution of potential values of $K_{1}$ and also examine the sensitivity of projections to different downscaling methodologies, though this was beyond the scope of this study. In particular, the use of methods which include physical drivers or those based on extreme value theory (EVT) should be compared, particularly for events with longer return periods than are examined here. Kallache et al. (2011) recently demonstrated some potential for the use of EVT for downscaling precipitation, whilst Hofherr \& Kunz (2010) have applied extreme value statistics to the output of a mesoscale atmospheric model to assess the extreme wind climatology of winter storms across Germany.

A further possibility for future development of this work would be to integrate projected future population and land use change and infrastructure development with wind hazard projections, developing projections of different roughness lengths, and thus wind correction factors for future scenarios. For example, the Tyndall Centre has developed population and high-resolution land use projections for London (Hall et al. 2009), which could be applied to the development of a vulnerability index combining socio-economic and climatological change. This approach is being tested in the CREW project for heatrelated hazards.

The projections presented here will be integrated with additional spatial information such as population data, critical infrastructure information or transport nodes, and may be combined with projections of 
other modelled hazards (pluvial and fluvial flooding, heat, water resources and subsidence) to define hazard 'hotspots'. Wind hazards have generally not been considered in city-scale impacts and adaptation studies (Hunt \& Watkiss 2011), so their inclusion represents a testing ground for a more broad-based assessment of potential climate change impacts on the city scale. Within the context of the current modelling limitations discussed above, they will thus help to provide local stakeholders with an improved understanding of the risks and vulnerabilities associated with current and future EWEs.

Acknowledgements. This work was undertaken as part of the CREW project which was funded by the Engineering and Physical Sciences Research Council (EPSRC) project no. EP/F037422/1. This work was also supported by a NERC post-doctoral Fellowship award to Dr H. Fowler (2006-2010) NE/D009588/1. We also thank the 4 anonymous reviewers for their constructive comments which helped improve the manuscript.

\section{LITERATURE CITED}

Alcamo J, Moreno JM, Nováky B, Bindi M and others (2007) Europe. In: Parry ML, Canziani OF, Palutikof JP, van der Linden PJ, Hanson CE (eds) Climate change 2007: impacts, adaptation and vulnerability. Contribution of Working Group II to the Fourth Assessment Report of the Intergovernmental Panel on Climate Change. Cambridge University Press, Cambridge, p 541-580

Bader J, Mesquita MDS, Hodges KI, Keenlyside N, Østerhus S, Miles M (2011) A review on Northern Hemisphere sea-ice, storminess and the North Atlantic Oscillation: observations and projected changes. Atmos Res 101(4): 809-834

Beniston M, Stephenson DB, Christensen OB, Ferro CAT and others (2007) Future extreme events in European climate: an exploration of regional climate model projections. Clim Change 81:71-95

Bernardin F, Bossy M, Chauvin C, Drobinski P, Rousseau A, Salameh T (2009) Stochastic downscaling method: application to wind refinement. Stochastic Environ Res Risk Assess 23:851-859

Blenkinsop S, Hallett S, Truckell I, Fowler HJ (2010a) The CREW project: towards a toolkit for the use of probabilistic climate change projections. Proc BHS 3rd Int Symp, Role of Hydrology in Managing Consequences of a Changing Global Environment, 19-23 July 2010, Newcastle upon Tyne

Blenkinsop S, Fowler HJ, Kilsby CG (2010b) Supplement to: Brown S, Boorman P, McDonald R, Murphy J (2009) Interpretation for use of surface wind speed projections from the 11-member Met Office Regional Climate Model ensemble. UKCP Technical Note, p 1-7, available at: http://badc.nerc.ac.uk/view/badc.nerc.ac.uk_ATOM_ dataent_ukmo-midas

Bottema M (1992) Wind climate and urban geometry. Report no. 92.63k, Technical University of Eindhoven

Brown S, Boorman P, Buonomo E, Burke E and others (2008) A climatology of extremes for the UK. A baseline for UKCP09. Met Office Hadley Centre, available at: http:// ukclimateprojections.defra.gov.uk/media.jsp?mediaid= 87915\&filetype $=$ pdf

Brown S, Boorman P, McDonald R, Murphy J (2009) Use and interpretation of surface wind projections from the 11member Met Office Regional Climate Model ensemble. UKCP Technical Note

BSI (British Standards Institute) (2005) EN 1991-1-4:2005 Eurocode 1: actions on structures. 1-4. General actionswind actions. BSI, London

Cagnazzo C, Manzini E (2009) Impact of the stratosphere on the winter tropospheric teleconnections between ENSO and the North Atlantic and European region. J Clim 22: 1223-1238

Christensen $\mathrm{JH}$, Hewitson B, Busuioc A, Chen A and others (2007) Regional climate projections. In: Solomon S, Qin D, Manning M, Chen Z and others (eds) Climate change 2007: the physical science basis. Contribution of Working Group I to the Fourth Assessment Report of the Intergovernmental Panel on Climate Change. Cambridge University Press, Cambridge

City of London (2010) Rising to the challenge. The City of London climate change adaptation strategy. 2010 update. City of London

Cook NJ (1985) The designer's guide to wind loading of building structures. 1. Background, damage survey, wind data and structural classification. Butterworths, London

Cook NJ (1990) The designer's guide to wind loading of building structures. 2 Static structures. Building Research Establishment Report. Butterworths, London

Cui Z, Cai X, Baker CJ (2004) Large-eddy simulation of turbulent flow in a street canyon. Q J R Meteorol Soc 130: 1373-1394

> Davy RJ, Woods MJ, Russell CJ, Coppin PA (2010) Statistical downscaling of wind variability from meteorological fields. Boundary-Layer Meteorol 135:161-175

> Donat MG, Leckebusch GC, Wild S, Ulbrich U (2010) Benefits and limitations of regional multi-model ensembles for storm loss estimations. Clim Res 44:211-225

- Efron B, Gong G (1983) A leisurely look at the bootstrap, the jackknife, and cross-validation. Am Stat 37:36-48

Efron B, Tibshirani R (1993) An introduction to the bootstrap. Chapman \& Hall, New York, NY

> Fowler HJ, Ekström M (2009) Multi-model ensemble estimates of climate change impacts on UK seasonal precipitation extremes. Int J Climatol 29:385-416

Fowler HJ, Kilsby CG (2007) Using regional climate model data to simulate historical and future river flows in northwest England. Clim Change 80:337-367

> Fowler HJ, Blenkinsop S, Tebaldi C (2007) Linking climate change modelling to impacts studies: recent advances in downscaling techniques for hydrological modelling. Int J Climatol 27:1547-1578

Fowler HJ, Cooley D, Sain SR, Thurston M (2010) Detecting change in UK extreme precipitation using results from the climateprediction.net BBC climate change experiment. Extremes 13:241-267

Hall JW, Dawson RJ, Walsh CL, Barker T and others (2009) Engineering cities: How can cities grow whilst reducing emissions and vulnerability? Newcastle University, Newcastle upon Tyne

> Hofherr T, Kunz M (2010) Extreme wind climatology of winter storms in Germany. Clim Res 41:105-123

Huebener H, Cubasch U, Langematz U, Spangehl T, Niehorster F, Fast I, Kunxe M (2007) Ensemble climate simulations using a fully coupled ocean-tropospherestratosphere general circulation model. Philos Trans R Soc Lond A 365:2089-2101 
Hunt A, Watkiss P (2011) Climate change impacts and adaptation in cities: a review of the literature. Clim Change 104:13-49

Hunt JCR, Poulton EC, Mumford JC (1976) The effects of wind on people: new criteria based on wind tunnel experiments. Build Environ 11:15-28

Jenkins GJ, Perry MC, Prior MJ (2008) The climate of the United Kingdom and recent trends. Met Office Hadley Centre, Exeter

Jenkins GJ, Murphy JM, Sexton DMH, Lowe JA, Jones P, Kilsby CG (2009) UK climate projections: briefing report. Met Office Hadley Centre, Exeter

Jones PD, Kilsby CG, Harpham C, Glenis V, Burton A (2009) UK climate projections science report: projections of future daily climate for the UK from the Weather Generator. University of Newcastle, Newcastle upon Tyne

> Jordan SC, Johnson T, Sterling M, Baker CJ (2008) Evaluating and modelling the response of an individual to a sudden change in wind speed. Build Environ 43: 1521-1534

Kallache M, Vrac M, Naveau P, Michelangeli PA (2011) Nonstationary probabilistic downscaling of extreme precipitation. J Geophys Res 116:D05113 doi:10.1029/2010 JD014892

Karl TR, Knight RW, Easterling DR (1999) Climate extremes: selected review and future research directions. Clim Change 42:309-325

Kjellström E, Bärring L, Jacob D, Jones R, Lenderink G, Schär C (2007) Modelling daily temperature extremes: recent climate and future changes over Europe. Clim Change 81(Supplement 1):249-265

Kjellström E, Nikulin G, Hannsson U, Strandberg G, Ullerstig A (2011) 21st century changes in the European climate: uncertainties derived from an ensemble of regional climate model simulations. Tellus 63A:24-40

Mayor of London (2007) Health issues in planning. Best practice guidance. Greater London Authority, London, available at: http://static.london.gov.uk/mayor/strategies/ sds/docs/bpg-health.pdf (accessed 18 January 2011)

Mayor of London (2008) The London Plan. Spatial development strategy for Greater London. Greater London Authority, London

Meehl GA, Stocker TF, Collins WD, Friedlingstein P and others (2007) Global climate projections. In: Solomon S, Qin D, Manning M, Chen Z and others (eds) Climate change 2007: the physical science basis. Contribution of Working Group I to the Fourth Assessment Report of the Intergovernmental Panel on Climate Change. Cambridge University Press, Cambridge

> Metje N, Sterling M, Baker CJ (2008) Pedestrian comfort using clothing values and body temperatures. J Wind Eng Ind Aerodyn 96:412-435

Murphy JM, Sexton DMH, Jenkins GJ, Boorman PM, and others (2010) UK climate projections science report: climate change projections. version 3, updated December 2010. Met Office Hadley Centre, Exeter

Najac J, Boé J, Terray L (2009) A multi-model ensemble approach for assessment of climate change impact on surface winds in France. Clim Dyn 32:615-634

Nikulin G, Kjellström E, Hannsson U, Strandberg G, Ullerstig A (2011) Evaluation and future projections of tem-

Editorial responsibility: Richard Katz,

Boulder, Colorado, USA perature, precipitation and wind extremes over Europe in an ensemble of regional climate simulations. Tellus 63A:41-55

Ordnance Survey (2009a) OS GB National grid shape file. Digimap: EDINA supplied service, available at: http:// edina.ac.uk/digimap/index.shtml (accessed 27 February 2009)

Ordnance Survey (2009b) OS landranger map series 1: 250000. Digimap: EDINA supplied service, available at: http://edina.ac.uk/digimap/index.shtml (accessed 27 April 2009)

Ordnance Survey (2009c) OS land-form PANORAMA DTM, 1:50000. Digimap: EDINA supplied service, available at: http://edina.ac.uk/digimap/index.shtml (accessed 20 April 2009)

$>$ Perry MC, Hollis DM (2005) The generation of monthly gridded datasets for a range of climatic variables over the UK. Int J Climatol 25:1041-1054

Pryor SC, Schoof JT, Barthelmie RJ (2005) Climate change impacts on wind speeds and wind energy density in northern Europe: empirical downscaling of multiple AOGCMs. Clim Res 29:183-198

Räisänen J, Hansson U, Ullerstig A, Döscher R and others (2004) European climate in the late 21st century: regional simulations with two driving global models and two forcing scenarios. Clim Dyn 22:13-31

- Rockel B, Woth K (2007) Extremes of near-surface wind speed over Europe and their future changes as estimated from an ensemble of RCM simulations. Clim Change 81(Supplement 1):267-280

> Salameh T, Drobinski P, Vrac M, Naveau P (2009) Statistical downscaling of near-surface wind over complex terrain in southern France. Meteorol Atmos Phys 103:253-265

Scaife AA, Spangehl T, Fereday DR, Cubasch U and others (2012) Climate change projections and stratospheretroposphere interaction. Clim Dyn 38:2089-2097

Schwierz C, Köllner-Heck P, Zenklusen Mutter E, Bresch DN, Vidale PL, Wild M, Schär C (2010) Modelling European winter wind storm losses in current and future climate. Clim Change 101:485-514

Sexton DMH, Murphy J (2010) Probabilistic projections of wind speed. UKCP Technical Note, Met Office Hadley Centre, Exeter

Smith C, Lawson N (2012) Identifying extreme climate event thresholds for greater Manchester, UK: examining the past to prepare for the future. Meteorol Appl 19:26-35

> Stathopoulos T (2006) Pedestrian level winds and outdoor human comfort. J Wind Eng Ind Aerodyn 94:769-780

> Ulbrich U, Pinto JG, Kupfer H, Leckebusch GC, Spangehl T, Reyers M (2008) Changing Northern Hemisphere storm tracks in an ensemble of IPCC climate change simulations. J Clim 21:1669-1679

Ulbrich U, Leckebusch GC, Pinto JG (2009) Extra-tropical cyclones in the present and future climate: a review. Theor Appl Climatol 96:117-131

> Wieringa J (1986) Roughness-dependent geographical interpolation of surface wind speed averages. Q J R Meteorol Soc 112:867-889

Wilby RL, Wigley TML (1997) Downscaling general circulation model output: a review of methods and limitations. Prog Phys Geogr 21:530-548

Submitted: March 28, 2011; Accepted: February 3, 2012

Proofs received from author(s): June 18, 2012 